\title{
A simplified and scalable synthesis of artesunate
}

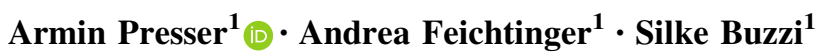

Received: 21 September 2016/Accepted: 25 October 2016/Published online: 2 December 2016

(c) The Author(s) 2016. This article is published with open access at Springerlink.com

\begin{abstract}
An efficient and economically viable approach for the large-scale conversion of artemisinin into the antimalarial frontline drug artesunate was developed. This advanced synthesis includes an $\mathrm{NaBH}_{4}$-induced reduction, followed by an esterification with succinic anhydride under basic conditions. The entire conversion follows the principles of green chemistry, i.e., application of reusable solvents.

\section{Graphical abstract}
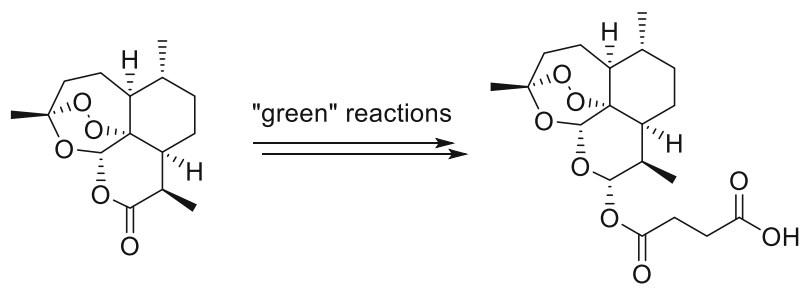

Keywords Antimalarial · Peroxides · Natural products . Reductions · Green chemistry

\section{Introduction}

Malaria, caused by parasitic protozoans of the Plasmodium type, still remains a life-threatening disease with about 600,000 death cases each year, with many of them being children under 5 years. The sesquiterpene endoperoxide

Armin Presser

armin.presser@uni-graz.at

1 Institute of Pharmaceutical Sciences, University of Graz, Graz, Austria artemisinin (1) [1, 2], is the lead component of the socalled artemisinin combination therapies (ACTs), which is currently the most valuable weapon in the fight against this disease. Several easily accessible artemisinin derivatives, including dihydroartemisinin (DHA, 2) and artesunate (3), exhibit potent antimalarial activity against drug-resistant malaria strains [3-5]. In addition, they also show remarkable activities against other parasites and various cancer types $[4,6]$.

Artemisinin was discovered in the 1970s as a result of an extensive screening of Chinese herbal extracts in the search of new antimalarial agents [7]. Currently, the primary method for the production of artemisinin is the isolation from dried leaves of the plant Artemisia annua. Shortcomings of existing processes are poor yields and environmental pollution [8]. Furthermore, the global supply of this life-saving drug exclusively from natural sources remains highly limited. As a result, several novel approaches for large-scale production of artemisinin have been developed [9-13].

ACT medications rely not only on the procurement of artemisinin, also the derivatives DHA (2, also known under its INN identification artenimol) and artesunate (3) became frontline drugs due to stronger activity and improved bioavailability compared to the parent compound [1, 14]. The transformation of artemisinin into artesunate was commonly realized by a two-step process involving the reduction with $\mathrm{NaBH}_{4}$ [15-19], $\mathrm{KBH}_{4}$ [20, 21] or diisobutylaluminium hydride (DIBAL) [22, 23], followed by esterification using succinic anhydride [24, 25]. However, these syntheses described in the scientific literature are not suitable for an industrial large-scale process because they require very low temperature, highly expensive or toxic reagents and solvents or provide only moderate yields. Recently, some continuous flow protocols 
for the preparation of $\mathbf{2}$ and $\mathbf{3}$ were published [26-28]. Flow protocols have some technical advantages over batch protocols. However, batch processing still dominates the manufacturing of pharmaceuticals today.

On the basis of our earlier studies sponsored by Medicines for Malaria Ventures (MMV) [29], we report herein a facile and scalable synthetic route for the preparation of dihydroartemisinin (2) and artesunate (3) from 1 in high yields following the principles of green chemistry, i.e., the minimization of waste, avoidance of toxic solvents, and elimination of unnecessary steps.

\section{Results and discussion}

Our initial work started with the well-described reduction of artemisinin with $\mathrm{NaBH}_{4}$ in methanol. THF or dioxane were also used as solvents [30]; however, because of ecological and economic reasons, the use of these solvents was ruled out [31-33]. DIBAL in $\mathrm{CH}_{2} \mathrm{Cl}_{2}$ seems to be a superior reagent for the conversion of artemisinin to DHA [23], but it is more expensive and requires extremely low temperature. The also known procedure with $\mathrm{KBH}_{4}$ in the presence of a phase-transfer catalyst [20] shows some inconsistencies and contains a rather hazy experimental part.

After assessing diverse instructions from the literature, we determined the most suitable conditions for the reduction of artemisinin: first, we identified the amount of $\mathrm{NaBH}_{4}$ required for the complete transformation. As a consequence of the competing methanol-induced solvolysis, a certain excess of the reagent is definitely required. It is known that the instability of $\mathrm{NaBH}_{4}$ in $\mathrm{MeOH}$ can be overcome by the addition of a base [34], but the extreme vulnerability of DHA towards small amounts of strong bases [21] excludes this approach. Apparently, the application of a lower reaction temperature leads to a slower decomposition of $\mathrm{NaBH}_{4}$ by $\mathrm{MeOH}$ [21]. As a consequence, the reaction time has to be kept short, and the reaction temperature kept as low as possible. Due to the decrease of the reaction temperature, the excess of $\mathrm{NaBH}_{4}$ could be considerably reduced as compared to the published instructions. However, a contamination of the reagent with traces of strong bases will also have a negative impact on the yield.

The best results were achieved when 2.5 equiv. of $\mathrm{NaBH}_{4}$ were added to a suspension of approx. $0.6 \mathrm{M}$ artemisinin in $\mathrm{MeOH}$ at $0-5{ }^{\circ} \mathrm{C}$ over $30 \mathrm{~min}$ and a total reaction time of $1 \mathrm{~h}$ (Scheme 1). Two different types of $\mathrm{NaBH}_{4}$, powder and granulate, were tested. Even though the yields are identical, the use of granulated material is preferred because the production of toxic dust during handling is minimized. Subsequently, the work-up conditions were optimized. After destroying the excess of $\mathrm{NaBH}_{4}$ with acetic or hydrochloric acid, DHA is usually precipitated by the addition of water. Through this procedure, DHA could be obtained in satisfactory yields (79-89\%) as published previously $[16,19,21]$. In an alternative strategy, the yield of DHA could be further enhanced by neutralization with $30 \%$ acetic acid/ $\mathrm{MeOH}$ at $0-5{ }^{\circ} \mathrm{C}$, concentration, and multiple extraction of the white residue using Et-OAc. Evaporation under reduced pressure provided $\mathbf{2}$ as a white crystalline powder in $98 \%$ yield, which can be used in the next step without further purification. To reduce the large consumption of Et-OAc, the solvent was distilled and reused.

Bulk solid DHA results solely as $\beta$-epimer of the lactol hemiacetal [35]. Addition of $\mathrm{CDCl}_{3}$ provides a solution consisting exclusively of $\boldsymbol{2} \boldsymbol{\beta}$, which equilibrates gradually to a 1:1 mixture of $2 \alpha$ and $\mathbf{2 \beta}$. The epimerization is clearly indicated by arising signals at $5.39 \mathrm{ppm}(\mathrm{H}-12 \alpha)$ and $4.75 \mathrm{ppm}(\mathrm{H}-10 \alpha)$ in the ${ }^{1} \mathrm{H}$ NMR spectrum (see Fig. 1). The equilibrium ratio is depending on the solvent [36]: in $\mathrm{CH}_{3} \mathrm{CN} / \mathrm{H}_{2} \mathrm{O}$ which we used for HPLC analysis, the relation of $2 \alpha$ and $2 \beta$ is $3: 1$.

Acylation of DHA (2) to artesunate (3) was first realized with succinic anhydride in the presence of pyridine as a base/solvent [24]. The use of catalytic DMAP was also reported [37] with a yield of $65 \%$. Aside from Chinese publications, there exist only marginal instructions [25] for the preparation of $\mathbf{3}$ so far. Also, a patent specification with $\mathrm{Et}_{3} \mathrm{~N}$ as base in acetone, THF, or dioxane promising yields up to $97 \%$ [38] was not reproducible [36]. Pharmaceutically approved artesunate is an $\alpha$-linked dihydroartemisinin hemisuccinate. It was reported that acylation of DHA in alkaline media led almost exclusively to $\alpha$-configured derivatives [35, 39]. An obvious reason may be the crowded environment of the axial hydroxyl in the $\beta$-epimer or the higher stability and thermodynamically favored conformation of $2 \alpha$. The classical esterification method using acid chlorides or anhydrides in pyridine (Einhorn method) requires anhydrous conditions. In our first attempt, we replaced the originally used pyridine by $\mathrm{Et}_{3} \mathrm{~N}$ and chose EtOAc as a reusable and ecologically more acceptable solvent. A supplemental addition of DMAP as well as the usage of anhydrous solvents appeared to be negligible. To further improve the reaction conditions, we investigated the stoichiometric ratio of the reagents. As shown in Table 1, the esterification occurred almost quantitatively with a 1.4fold excess of succinic anhydride using 0.6 equiv. of $\mathrm{Et}_{3} \mathrm{~N}$. The reaction can take place at RT or even higher temperature (up to $50{ }^{\circ} \mathrm{C}$ ) without any difference in yield.

Unfortunately, the recycling of Et-OAc by distillation leaves a water content up to $8.5 \%$ [40] which negatively affects the yield when reused solvent was applied. This difficulty was overcome by changing the reaction medium to 
Scheme 1<smiles>CC1C(=O)O[C@H]2O[C@]3(C)CC[C@@H]1[C@H](C)CC[C@H]23</smiles>

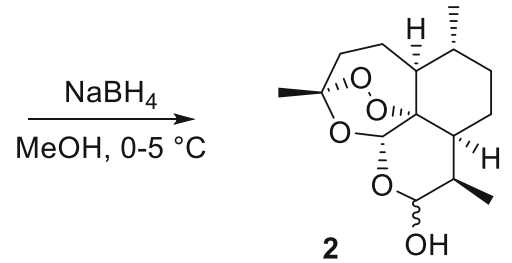

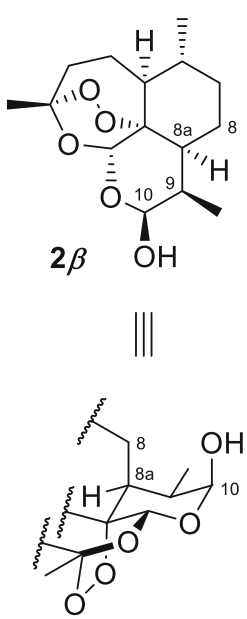

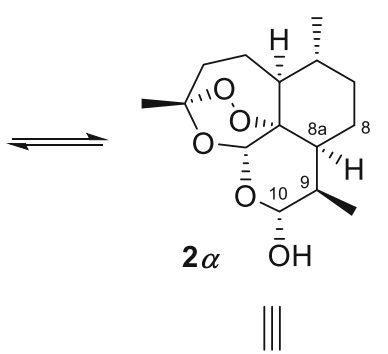<smiles>O=C1CCC(=O)O1</smiles>

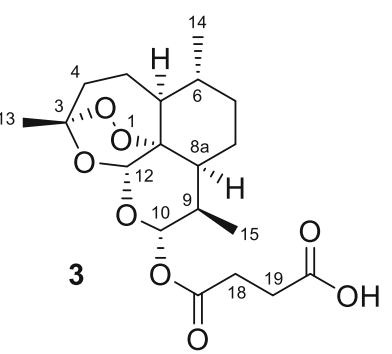

isopropyl acetate. Because of the lower moisture content (1.5\% determined via Carl Fischer titration), even after recycling of the solvent, artesunate was obtained in the same excellent yields. ${ }^{1} \mathrm{H}$ NMR spectroscopic analyses confirmed that exclusively $\alpha$-artesunate was formed; the large transdiaxial coupling of $\mathrm{H}-10$ at $5.67 \mathrm{ppm}\left(J_{10,9}=9.7 \mathrm{~Hz}\right)$ pinpoints the requested configuration at $\mathrm{C}-10$.

\section{Conclusion}

In summary, we report on the development of an advanced synthetic route for the conversion of the natural product artemisinin into semisynthetic artesunate by $\mathrm{NaBH}_{4}$-induced reduction and subsequent esterification under basic conditions as pivotal steps. Using our synthetic approach, feasibility and scalability of the synthesis can be dramatically improved while the overall yield remains among the best so far documented. This procedure should favorably complement the existing routes and may represent an additional entry to the production of artesunate at low costs.

\section{Experimental}

Melting points were obtained on a digital melting point apparatus (Electrothermal IA 9200). The NMR spectra were measured on a Varian Unity Inova 400 instrument (at $298 \mathrm{~K}$ ) using 5-mm tubes. Chemical shifts were given in parts per million (ppm); the tetramethylsilane (TMS) resonance $(0.00 \mathrm{ppm})$ was used as internal standard. Coupling constants $(J)$ were reported in Hertz $(\mathrm{Hz}) .{ }^{1} \mathrm{H}$ and ${ }^{13} \mathrm{C}$ resonances were assigned using ${ }^{1} \mathrm{H},{ }^{1} \mathrm{H}$ and ${ }^{1} \mathrm{H},{ }^{13} \mathrm{C}$ correlation spectra. ${ }^{1} \mathrm{H}$ and ${ }^{13} \mathrm{C}$ resonances are numbered as given in the formulae. The signals marked with an asterisk are interchangeable. The IR spectra were recorded on an ALPHA FT-IR-spectrometer (Bruker). Optical rotation was determined on a P-2000 polarimeter (Jasco). The water content of the solvents was quantified via Carl Fischer titration on a TitroLine $7500 \mathrm{KF}$ (SI Analytics). HPLC separations were performed on a Merck Hitachi HPLC apparatus D6000A consisting of a pump L6200 and UVVis-detector L4250. Diastereomer separation was achieved using a LiChrospher ${ }^{\circledR} 100 \mathrm{RP}-18(5 \mu \mathrm{m}, 125 \times 3 \mathrm{~mm}$, Merck) HPLC column, operated at $30{ }^{\circ} \mathrm{C}$. Each 10-min chromatographic run was carried out at a flow rate of $0.5 \mathrm{~cm}^{3} / \mathrm{min}$ with an isocratic mobile phase consisting of acetonitrile (20\%) and Millipore water $(80 \%)$. Runtime was $10 \mathrm{~min}$ and detection wavelength was $224 \mathrm{~nm}$. The purity of artesunate was checked by HPLC analysis performed on an Agilent 1200 series equipped with an autosampler, a quaternary pump system and a photodiode array detector. An Agilent Zorbax SP-C18 column (particle size $3.5 \mu \mathrm{m} ; 2.1 \times 150 \mathrm{~mm}$ with guard cartridge) was used 

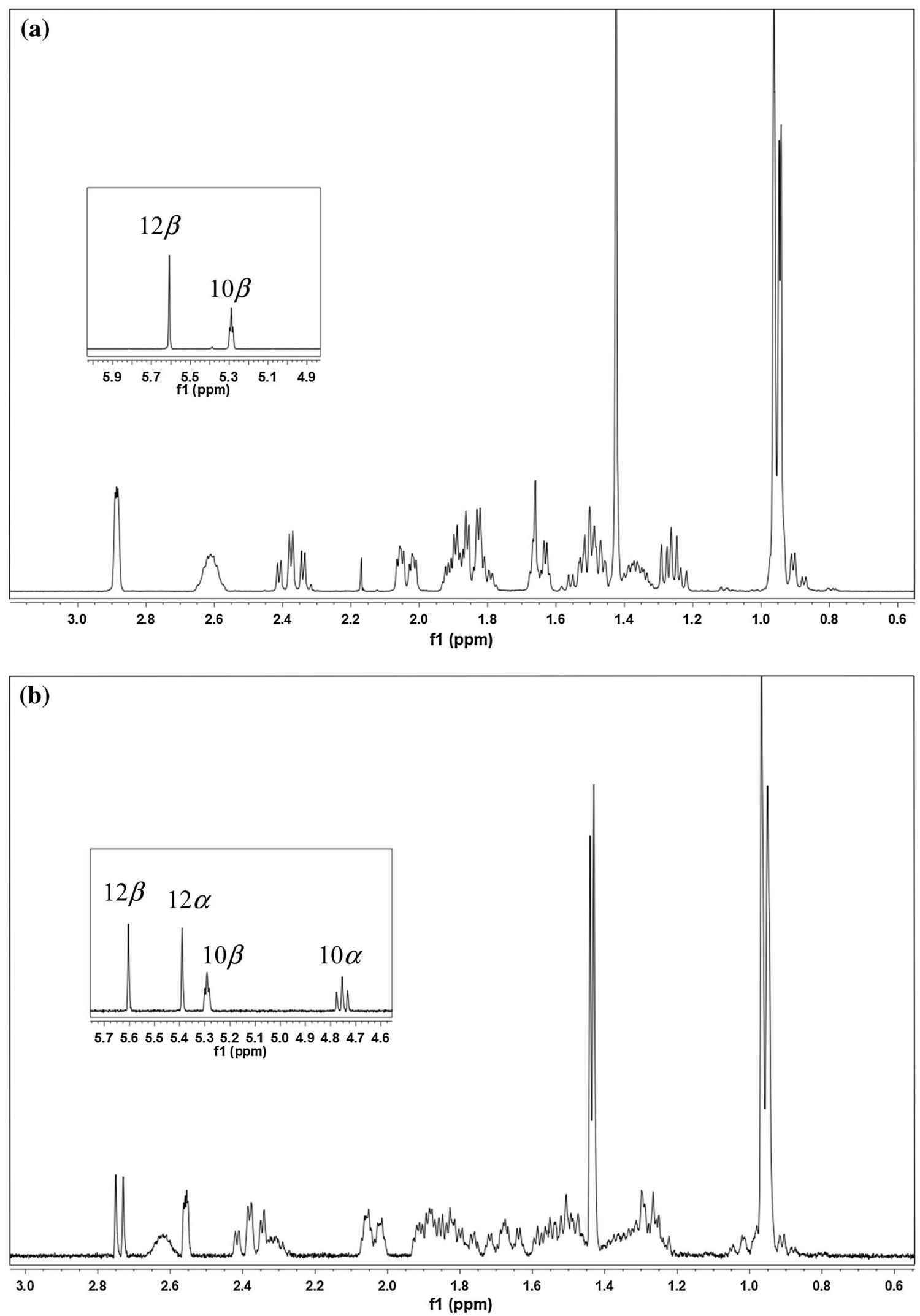

Fig. $1 \quad{ }^{1} \mathrm{H}$ NMR of DHA (2): immediately after dissolution (a) and after $12 \mathrm{~h}$ (b) 
Table 1 Synthesis of artesunate with different stoichiometric ratios and temperatures

\begin{tabular}{lllll}
\hline Entry & Succ. anhydr./equiv & $\mathrm{Et}_{3} \mathrm{~N} /$ equiv & Temp. $/{ }^{\circ} \mathrm{C}$ & Yield/\% $^{\mathrm{a}}$ \\
\hline 1 & 2.0 & 1.1 & 25 & 86 \\
2 & 1.5 & 1.1 & 25 & 81 \\
3 & 1.5 & 1.1 & 50 & 80 \\
4 & 1.2 & 1.1 & 25 & 58 \\
5 & 1.5 & 0.8 & 25 & 85 \\
6 & 1.3 & 0.8 & 25 & 83 \\
7 & 1.3 & 0.6 & 25 & 89 \\
8 & 1.3 & 0.6 & 40 & 88 \\
9 & 1.4 & 0.6 & 25 & 94 \\
\hline
\end{tabular}

Reaction conditions: dihydroartemisinin $(2,35.2 \mathrm{mmol})$, succinic anhydride and $\mathrm{Et}_{3} \mathrm{~N}$ as stated above, $30 \mathrm{~cm}^{3}$ solvent; the reactions were monitored by TLC until the apparent consumption of the limiting substrate

${ }^{a}$ Isolated yield at a flow rate of $0.30 \mathrm{~cm}^{3} / \mathrm{min}$. The chromatographic method was performed with a gradient of acetonitrile (A) in Millipore water (B), both with each $0.1 \% \mathrm{HCOOH}$, from 10 to $90 \% \mathrm{~A}$ in $\mathrm{B}$ within $20 \mathrm{~min}$, then to $100 \% \mathrm{~A}$ within $5 \mathrm{~min}$ followed by returning to starting conditions within $1 \mathrm{~min}$ and re-equilibration for $8 \mathrm{~min} .10 \mathrm{~mm}^{3}$ of sample was injected and detection was done at $220 \mathrm{~nm}$. Materials: TLC was carried out on Merck TLC plates (silica gel $60 F_{254} 0.2 \mathrm{~mm}, 200 \times 200 \mathrm{~mm}$ ). TLCs were visualized by spraying with cerium(IV) sulfate/ammonium molybdate and subsequent heating with a heat gun. The solvents were concentrated by rotary evaporation below $50{ }^{\circ} \mathrm{C}$. Purity and homogeneity of compounds were assessed by TLC and HPLC methods.

\section{(3R,5aS, 6R, 8aS,9R,10S,12R,12aR)-Decahydro-3,6,9-tri- methyl-3,12-epoxy-12H-pyrano[4,3-j]- \\ [1,2]benzodioxepin-10-ol (dihydroartemisinin, 2)}

Artemisinin (10.0 g, $35.4 \mathrm{mmol}$ ) was suspended in $60 \mathrm{~cm}^{3}$ $\mathrm{MeOH}$ and cooled in an ice bath to $0-5{ }^{\circ} \mathrm{C}$. To the suspension, $3.35 \mathrm{~g}$ of $\mathrm{NaBH}_{4}(88.5 \mathrm{mmol})$ was added in small portions over a period of $30 \mathrm{~min}$. After the addition of $\mathrm{NaBH}_{4}$ was complete, the reaction was allowed to reach ambient temperature and was stirred vigorously under $\mathrm{Ar}$ until the TLC showed complete consumption of $\mathbf{1}$ ( $\sim 30 \mathrm{~min}$ ). The mixture was neutralized ( $\mathrm{pH} 5-6)$ with $30 \% \mathrm{AcOH} / \mathrm{MeOH}$, concentrated under reduced pressure and finally lyophilized. The white residue was extracted with Et-OAc several times. The combined Et-OAc extracts were filtered and evaporated to dryness to give $9.87 \mathrm{~g}$ (98\%) DHA as a white crystalline powder, which can be used in the next step without further purification. $R_{\mathrm{f}}=0.46$ $\left(\mathrm{CH}_{2} \mathrm{Cl}_{2}: \mathrm{MeOH}=20: 1\right)$, m.p.: $150-151{ }^{\circ} \mathrm{C}$ (Ref. [41], 152-153 $\left.{ }^{\circ} \mathrm{C}\right)$. The spectroscopic data were found to be identical with the ones described in Refs. [41-43].
(3R,5aS,6R,8aS,9R,10S,12R,12aR)-Decahydro-3,6,9-trimethyl-3,12-epoxy-12H-pyrano[4,3-j]-

[1,2]benzodioxepin-10-ol, hydrogen succinate

(artesunate, 3)

A solution of $4.93 \mathrm{~g}$ succinic anhydride (49.2 mmol) in $30 \mathrm{~cm}^{3}$ isopropyl acetate was treated under Ar with $2.94 \mathrm{~cm}^{3} \mathrm{Et}_{3} \mathrm{~N}$ (21.1 mmol). To this solution, $10.0 \mathrm{~g}$ of 2 (35.2 mmol) was successively added over a period of $30 \mathrm{~min}$ and the mixture was stirred at ambient temperature for $4 \mathrm{~h}$. Then, it was quenched with $\mathrm{H}_{2} \mathrm{O}$ and $\mathrm{H}_{2} \mathrm{SO}_{4}(2 \mathrm{~N})$ until $\mathrm{pH} 5$ was reached and stirred for a few minutes to achieve phase separation. The aqueous phase was extracted thoroughly with isopropyl acetate and the combined organic layers were concentrated under reduced pressure providing almost pure $\alpha$-artesunate (impurities $<1 \%$ ) as fine white needles. Yield $12.7 \mathrm{~g}$ (94\%).

A batch size over $50 \mathrm{~g}$ DHA requires a modified workup: After quenching with a small amount of $\mathrm{H}_{2} \mathrm{O}$ and neutralization with $\mathrm{H}_{2} \mathrm{SO}_{4}(2 \mathrm{~N})$, the mixture was diluted with isopropyl acetate and heated to $50{ }^{\circ} \mathrm{C}$ to dissolve precipitated 3. The organic layer was washed with warmish $\mathrm{H}_{2} \mathrm{O}$ and concentrated under reduced pressure providing $\alpha$ artesunate as described above. $R_{\mathrm{f}}=0.27 \quad(\mathrm{CH}: \mathrm{Et}-$ $\mathrm{OAc}=1: 1)$, m.p.: $131-133{ }^{\circ} \mathrm{C}\left(\mathrm{MeOH}: \mathrm{H}_{2} \mathrm{O}=1: 2\right)$ (Ref. [39], $\left.135^{\circ} \mathrm{C}\right)$. The spectroscopic data were found to be identical to the ones described in Refs. [39, 44]. Although the crystal structure of $\mathbf{3}$ is already known [39], to the best of our knowledge, a complete assignment of the NMR signals has never been published: ${ }^{1} \mathrm{H}$ NMR $(400 \mathrm{MHz}$, DMSO- $\left.d_{6}\right): \delta=5.67(\mathrm{~d}, J=9.7 \mathrm{~Hz}, 1 \mathrm{H}, \mathrm{H}-10), 5.56(\mathrm{~s}$, 1H, H-12), 2.63-2.58 (m, 2H, H-18', H-19'), 2.53-2.48 (m, $\left.2 \mathrm{H}, \mathrm{H}-18^{\prime \prime}, \mathrm{H}-19^{\prime \prime}\right), 2.35-2.23$ (m, 1H, H-9), $2.18(\mathrm{td}$, $\left.J=13.9,3.9 \mathrm{~Hz}, 1 \mathrm{H}, \mathrm{H}-4^{\prime}\right), 2.00(\mathrm{dt}, J=13.9,3.9 \mathrm{~Hz}$, $\left.1 \mathrm{H}, \mathrm{H}-4^{\prime \prime}\right), \quad 1.81\left(\mathrm{dq}, \quad J=10.3,3.5 \mathrm{~Hz}, 1 \mathrm{H}, \mathrm{H}-5^{\prime}\right)$, 
1.67-1.61 (m, 1H, H-8 $), 1.64-1.57$ (m, 1H, H-7'), 1.58-1.51 (m, 1H, H-8a), 1.48-1.41 (m, 1H, H- $\left.8^{\prime \prime}\right)$, 1.47-1.37 (m, 1H, H-6), 1.36-1.27 (m, 1H, H-5"), 1.29 (s, 3H, H-13), 1.19 (dd, $J=11.3,6.4 \mathrm{~Hz}, 1 \mathrm{H}, \mathrm{H}-5 \mathrm{a})$, $1.02-0.88$ (m, 1H, H-7"), 0.89 (d, $J=6.4 \mathrm{~Hz}, 3 \mathrm{H}, \mathrm{H}-14)$, 0.77 (d, $J=7.1 \mathrm{~Hz}, \quad 3 \mathrm{H}, \quad \mathrm{H}-15) \quad$ ppm.; ${ }^{13} \mathrm{C} \quad \mathrm{NMR}$ (100 MHz, DMSO- $\left.d_{6}\right): \delta=173.7$ (C-20), 171.5 (C-17), 104.0 (C-3), 92.2 (C-10), 91.1 (C-12), 80.3 (C-12a), 51.6 (C-5a), 45.0 (C-8a), 36.4 (C-4, C-6), 34.2 (C-7), 32.1 (C-9), 29.2* (C-18), 28.9* (C-19), 26.0 (C-13), 24.7 (C-5), 21.5 (C-8), 20.5 (C-14), 12.2 (C-15) ppm.

Acknowledgements Open access funding provided by University of Graz. We are grateful to Priv.-Doz. W. Schuehly for discussions, to the MMV and the German Medical Aid Organization action medeor e.V. for financial support.

Open Access This article is distributed under the terms of the Creative Commons Attribution 4.0 International License (http:// creativecommons.org/licenses/by/4.0/), which permits unrestricted use, distribution, and reproduction in any medium, provided you give appropriate credit to the original author(s) and the source, provide a link to the Creative Commons license, and indicate if changes were made.

\section{References}

1. Chang Z (2016) Sci China Life Sci 59:81

2. Edikpo NJ, Adikwu E (2013) Br J Pharmacol Toxicol 4:241

3. Ploypradith P (2004) Acta Trop 89:329

4. Ansari MT, Saify ZS, Sultana N, Ahmad I, Saeed-Ul-Hassan S, Tariq I, Khanum M (2013) Mini Rev Med Chem 13:1879

5. Visser BJ, van Vugt M, Grobusch MP (2014) Expert Opin Pharmacother 15:2219

6. Liu Y-X, Wu W, Liang Y-J, Jie Z-L, Wang H, Wang W, Huang Y-X (2014) Molecules 19:15058

7. Tu Y (2011) Nat Med 17:1217

8. Malwade CR, Qu H, Rong B-G, Christensen LP (2013) Ind Eng Chem Res 52:7157

9. Chen H-J, Han W-B, Hao H-D, Wu Y (2013) Tetrahedron 69:1112

10. Corsello MA, Garg NK (2015) Nat Prod Rep 32:359

11. Turconi J, Griolet F, Guevel R, Oddon G, Villa R, Geatti A, Hvala M, Rossen K, Goller R, Burgard A (2014) Org Process Res Dev 18:417

12. Amara Z, Bellamy JFB, Horvath R, Miller SJ, Beeby A, Burgard A, Rossen K, Poliakoff M, George MW (2015) Nat Chem 7:489

13. Burgard A, Gieshoff T, Peschl A, Hoerstermann D, Keleschovsky C, Villa R, Michelis S, Feth MP (2016) Chem Eng J 294:83

14. Cui L-W, Su X-Z (2009) Expert Rev Anti Infect Ther 7:999

15. Lin AJ, Klayman DL, Milhous WK (1987) J Med Chem 30:2147

16. Brossi A, Venugopalan B, Dominguez Gerpe L, Yeh HJC, Flippen-Anderson JL, Buchs P, Luo XD, Milhous W, Peters W (1988) J Med Chem 31:645
17. Shrimali M, Bhattacharya AK, Jain DC, Bhakuni RS, Sharma RP (1998) Indian J Chem Sect B Org Chem Incl Med Chem 37B: 1161

18. Ferreir JFS, Janick J (1996) Phytochemistry 41:97

19. Liu Y, Liu Z, Shi J, Chen H, Mi B, Li P, Gong P (2013) Molecules 18:2864

20. Wei G-F, Liao X-J, Pan G-Y, Huang Z-L, Cheng J-S, He Y-C (2010) J Nat Prod 3:161

21. Boehm M, Fuenfschilling PC, Krieger M, Kuesters E, Struber F (2007) Org Process Res Dev 11:336

22. Ma J, Katz E, Kyle DE, Ziffer H (2000) J Med Chem 43:4228

23. Avery MA, Mehrotra S, Johnson TL, Bonk JD, Vroman JA, Miller R (1996) J Med Chem 39:4149

24. China Cooperative Research Group on Qinghaosu and Its Derivatives as Antimalarials (1982) J Tradit Chin Med 2:9

25. Chekem L, Wierucki S (2007) Phytotherapie 5:90

26. Fan X, Sans V, Yaseneva P, Plaza DD, Williams J, Lapkin A (2012) Org Process Res Dev 16:1039

27. Gilmore K, Kopetzki D, Lee JW, Horvath Z, McQuade DT, Seidel-Morgenstern A, Seeberger PH (2014) Chem Commun 50:12652

28. Yaseneva P, Plaza D, Fan X, Loponov K, Lapkin A (2015) Catal Today 239:90

29. Buzzi S, Presser A, von Freyhold M (2007) Determining a viable protocol for the derivatisation of artemisinin into dihydroartemisinin and into artesunate. A report commissioned by MMV. http://www.mmv.org

30. Bhakuni RS, Kahol AP, Singh T, Khanuja SPS (2004) Single-pot conversion of artemisinin to artesunic acid. Int. Pat. WO 2004/050661 A1, Jun 17, 2004; (2004) Chem Abstr 141:54501

31. Prat D, Hayler J, Wells A (2014) Green Chem 16:4546

32. Prat D, Wells A, Hayler J, Sneddon H, McElroy CR, AbouShehada S, Dunn PJ (2016) Green Chem 18:288

33. Alder CM, Hayler JD, Henderson RK, Redman AM, Shukla L, Shuster LE, Sneddon HF (2016) Green Chem 18:3879

34. Jensen EH (1954) A study on sodium borohydride. Nyt Nordisk Forlag Arnold Busck A/S, Copenhagen

35. Luo XD, Yeh HJC, Brossi A, Flippen-Anderson JL, Gilardi R (1984) Helv Chim Acta 67:1515

36. Haynes RK (2006) Curr Top Med Chem 6:509

37. Li Y, Yu P, Chen Y, Ji R (1982) Huaxue Xuebao 40:557

38. Ognyanov IV, Konakchiev AN, Haenni R (1996) Process for the production of dihydroartemisinin hemisuccinate. Eur. Pat. EP 736535 A1, Oct 9, 1996; (1996) Chem Abstr 125:301268

39. Haynes RK, Chan H-W, Cheung M-K, Lam W-L, Soo M-K, Tsang H-W, Voerste A, Williams ID (2002) Eur J Org Chem:113

40. Merriman RW (1913) J Chem Soc. Trans 103:1790

41. Njogu PM, Gut J, Rosenthal PJ, Chibale K (2013) ACS Med Chem Lett 4:637

42. Pathak AK, Jain DC, Sharma RP (1995) Indian J Chem Sect B Org Chem Incl Med Chem 34B:992

43. Sy L-K, Hui S-M, Cheung K-K, Brown GD (1997) Tetrahedron 53:7493

44. Nyadong L, Harris GA, Balayssac S, Galhena AS, Malet-Martino M, Martino R, Parry RM, Wang MD, Fernandez FM, Gilard V (2009) Anal Chem 81:4803 